\title{
Reducing the effect of email interruptions on employees
}

\author{
Thomas Jackson $^{\mathrm{a}, \mathrm{b}, *}$, Ray Dawson ${ }^{\mathrm{a}}$, Darren Wilson ${ }^{\mathrm{b}}$ \\ ${ }^{a}$ Computer Science Department, Loughborough University, Loughborough, Leicestershire LE11 3TU, UK \\ ${ }^{\mathrm{b}}$ The Danwood Group, Harrisson Place, Lincoln LN6 3DG, UK
}

\begin{abstract}
It is generally assumed that because it is not necessary to react to email messages when they arrive, employees will read their messages in their own time with minimum interruption to their work. This research has shown that email messages do have some disruptive effect by interrupting the user. Employees at the Danwood Group in the UK were monitored to see how they used email. It was found that most employees had their email software check for incoming messages every $5 \mathrm{~min}$ and responded to the arrival of a message within $6 \mathrm{~s}$. A recovery time between finishing reading the email and returning to normal work also existed though it was shorter than published recovery times for a telephone interrupt.

This analysis has suggested that a number of methods can be employed to reduce this interrupt effect. Employee training, changing the settings and modes of using the email software and the introduction of a one line email facility are all shown to have beneficial effects. This has led to a series of recommendations that will enable the Danwood Group to make better use of email communication and increase employee effectiveness.
\end{abstract}

(C) 2003 Elsevier Science Ltd. All rights reserved.

Keywords: Email; Employee interruptions; Workplace communication; Productivity

\section{Introduction}

Human communication is a dynamic ongoing process. It is the process that enables employees to work together to achieve cooperation and to interpret ever-changing workplace needs and activities. The word 'communicate' is itself a semantic trap. As an active verb its purpose is to give information about the subject of the verb, the communicator, but by definition communication is a two-party activity, which requires a receiver as well as a transmitter. Human communication does not start and stop. People are constantly involved in communicating with themselves and

\footnotetext{
*Corresponding author. Computer Science Department, Loughborough University, Loughborough, Leicestershire LE11 3TU, UK. Tel.: + 44-1509-228231; fax: +44-1509-211586.

E-mail address: t.w.jackson@lboro.ac.uk (T. Jackson).
} 
with others, especially in the workplace. They are immersed in a sea of messages and meanings. Employees must be able to recognise and interpret the wide variety of messages available to them that enable them to respond appropriately to different people and situations. Human beings must communicate (Watzlawick, Beavin, \& Jackson, 1967). Communication is an inevitable reality of organisational membership and of life in general.

Effective communication has positive returns and, by executives' own vote, no aspect of a manager's performance is of greater importance to his or her success than communication (Fielden, 1960). In the Harvard Business Review article, "What helps or harms promotability?', Garda Bowman (1964) discovers the qualities that characterise promotable executives. She reports that the ability to communicate is at the highest rung (out of 8 rungs) of the ladder to promotion. With the widespread acceptance of computer-mediated communication technology, it stands to reason that the ability to communicate will also reflect the ability to communicate effectively with all types of communication media available.

A problem is that technology often magnifies shortfalls in communication skills (Frazee, 1996). Most are not taught how to be effective electronic communicators (Nantz \& Drexel, 1995) and a constant barrage of less-than-useful email messages disrupts workflow and robs employees of productive time (Frazee, 1996). It has been revealed that more than $65 \%$ of all email messages failed to leave receivers enough information to enable them to act on the message (Frazee, 1996). No company can afford such information incompetence (Davenport, 1997) but, as many studies are discovering, email use is growing at an increasing rate. A study by EdWel \& Company, a Chicago-based consulting and training firm, discovered that some individuals receive 80-100 email messages per day (Frazee, 1996). Average email users were said to receive approximately 15 messages per day and spend almost 50 min merely reading those messages (Frazee, 1996). Lynne Markus found in her survey that $22 \%$ of survey respondents reported sending between 0 and 5 messages per day, 53\% reported sending between 6 and 30 email messages per day; and 25\% reported sending more than 21 messages per day (Markus, 1994).

Little empirical research has been carried out into how email systems are used and the "hard" costs of running such a system in terms of the time an employee spends using the email facility. We still have much to learn about interactions among computer-mediated communication technologies, new organisational forms, and changes in work and communication (Daft \& Lewin, 1993), but the ability to monitor email now provides organisations with the opportunity to improve communication practices. Email is becoming an integral part of the communication structure within organisations, but the costs and benefits are not being assessed. Communication is carried out in many different forms, but the common underlying motive of communication is to improve working practices and to increase employee effectiveness.

\section{Interruptions}

Research carried out by Solingen into communication interrupts showed 15-20\% of an employee's effort is spent dealing with interrupts and in real terms 15-20 min per interrupt (Solingen, Berghout, \& Latum, 1998). An interrupt is defined as "any distraction that makes a developer stop his planned activity to respond to the interrupt's initiator". There were three types of interrupts defined: personal visits, telephone calls and emails. Personal visits and telephone calls 
caused $90 \%$ of all interrupts and email caused the rest. The results showed the effort spent on interrupts required approximately $20 \mathrm{~min}$ for each occurrence, including the time spent handling the interrupt, and that the average developer receives three to five interrupts per day. This consumes roughly $1-1.5 \mathrm{~h}$ per day of the developer's time.

DeMarco reported that the recovery time after a phone call interruption is at least 15 min, thus increasing the amount of time spent on interrupts a day (DeMarco \& Lister, 1987). However, DeMarco's research was carried out using software developers as the subjects. The highly creative nature of a software developer's job means they are likely to require extra time to recover from an interrupt compared to other job roles. This may account for the surprisingly long, 15 min recovery time. So far, there has been no reported empirical research into how long it takes to recover from an email interrupt. This could be because of the perception of email as causing a minimal interrupt. DeMarco suggests that the only difference between a phone call and an electronic mail message is that the phone call interrupts and the email does not, as recipients deal with emails at their own convenience (DeMarco \& Lister, 1999). This paper reports detailed research to determine the frequency of email interrupts and if there is such a phenomenon as an interrupt recovery time for email and, if there is, to discover if there is a "hard" cost associated with an email interruption.

Recent work-related interruption research has focused on the influence of noise on performance (Broadbent, 1979), the effects of interruptions in terms of technical problems and errors in industrial production (Hartley, Morrison, \& Arnold, 1973; Rasmussen, 1986) and the effects of computer breakdowns, rest breaks etc. on performance (Johansson \& Aronsson, 1984; Boucsein, 1989, 1993; Henning, Sauter, Salvendy, \& Krieg, 1989). An important difference between the older (before 1970) and the more recent investigations is that interruptions were used as a technique for studying psychological factors such as motivation. In later studies, interruptions are more or less treated as a phenomenon in themselves.

Apart from having effects on work outcomes, interruptions can also affect the personal state, in particular the emotions of the worker. Already in 1928, Ovsiankina mentioned the existence of negative emotions as a result of interruptions as subjects felt irritated. Mandler, first in 1964 and later in 1975 and 1984, formulated the relation between interruptions and emotions in more detail. He believed that another phenomenon is involved in the interruption process, besides the tendency to complete, namely, an emotional response. This response can direct workers' behaviour and it does not emerge unless an organised response has been interrupted. So far, no study has yet addressed the issue of emotions in interrupted work, although some researchers have acknowledged its importance (Briner, 1995; Pekrun \& Frese, 1992). Nevertheless, it is a common feeling that interrupts are annoying and any research that can lead to a reduction of interruption effects is therefore to be welcomed.

\section{Recording the metrics}

In order to determine the frequency and extent of email interrupts it was decided that it was necessary to record actual experience rather than ask company employees in a survey. Because interrupts can affect a person's emotional state (Ovsiankina, 1928; Mandler, 1964, 1975) the reported effects of interrupts are bound to be subject to some bias. Recording actual interrupt 
effects will give a far more accurate picture on which to base any change in company policy and advice to employees on methods to reduce email interrupts.

The experiments to examine email behaviour were conducted at the Danwood Group, a company of about 500 employees in the UK. 15 employees at all levels of the company hierarchy formed the basis of the case study. Although the results obtained could only be relevant to the Danwood Group, the company, nevertheless represented a typical medium sized company in the UK and the results are likely to give some indication of interrupt effects in the many similar companies in the UK.

There were numerous ways the interrupt recovery time metrics could have been recorded. An obvious way was to record the employees at their desk, carrying out various activities and capturing them on a camcorder. However, the Danwood Group board of directors deemed this method in appropriate, as it would not be acceptable to employees. Another possibility would be to have an actual person watching the employee at their desk from a distance. This method would have probably produced distorted results due to the employee knowing they are being monitored through the constant presence of the monitor (Mayo, 1933). The last option considered was to use computer software to monitor the employee. A number of different applications were reviewed to find the most appropriate to record interrupt recovery times. These included, Windows Virtual Network Computing (WinVNC), Back Orifice 2000, Lotus SmartCAM, I-SPY and Windows Ranger (Richardson Tristan, Stafford-Fraser Quentin, Wood Kenneth, \& Hooper Andy, 1998; DilDog, 2000; Lotus, 2000; Visionsoft, 2000; Sentinel, 2000). Many had a number of restrictions, such as, lack of reliability, no access to the monitoring source code, inappropriate system tray icons, too slow or excessive amounts of media required to record an employee at work for a full day. It was decided that WinVNC would be used alongside a video recorder to record employee activities throughout the day.

WinVNC is a remote display system that allows viewing of a remote computer 'desktop' environment, not only on the machine where it is running but also from anywhere on the Internet and from a wide variety of machine architectures (Cambridge, AT\&T Laboratories, 2000). WinVNC was set-up on both the client and server side to allow monitoring of the employee's machines remotely. A modified version of the WinVNC program was used that did not show the icon informing the users they were being monitored. The server side had a video recorder attached to the computer, to record all the employees' activities on the screen to videotape.

The monitoring of employees actions on their computers raises important ethical questions. The Danwood Group management did not want employees to feel they were spying on them. However, it was also recognised that in order to obtain unbiased information it was important that the employees behaved normally, which they are unlikely to do if they know they are being monitored. The company staff handbook, which is a company booklet accepted by all staff, does allow for the monitoring of email within the company. However, to maintain goodwill, it was agreed that the monitoring of email should be conducted under the following strict conditions:

1. All recordings of employee activities would only be viewed by Loughborough University, who were carrying out the research in conjunction with the company.

2. The results would be fed back to the company as overall totals, averages and trends-no information on any individuals would be supplied to the company.

3. The results would be used to benefit the company as a whole, including all its employees. 
The information that could be obtained from the monitoring was as follows:

1. The frequency that the email software checked for incoming messages.

2. The nature of the notification of the incoming mail to the users.

3. The nature of the email messages.

4. The time spent reading email.

5. The recovery time after dealing with an email message for employees to resume their previous activities.

A total of 15 employees were monitored over 28 working days, which led to over 180 hours of videotape recordings. All the employees email interactivity was recorded and analysed as well as the activities leading up to and after the email interruption. The definition of an email interrupt is any email distraction that makes an employee stop their planned activity. The recovery time was calculated by recording the amount of time that it took an employee to return to their work at the same work rate at which they left it. This required an element of judgement by the person reviewing the recorded material. However, there was usually a fairly clear point where the user ceased to move the mouse around the screen and jump between screens trying to pick up their train of thought and the production of useful work. Although this may be regarded as a rather inexact measure, in fact, the authors believe that in reality interpretation of the activities by different people would not have given any significant difference in the results.

\section{Results of monitoring email interruptions}

Out of the employees monitored 70\% used Microsoft Outlook 2000 and 30\% used Microsoft Outlook 97. All the employees had a new "email arrived" icon appear in the system tray when new email arrived and $57 \%$ of the employees also had a new "email arrived" pop-up dialogue box appear. The majority of the employees monitored had their email software check for incoming messages every $5 \mathrm{~min}$. This was set by default when the software was first installed.

It took the employees an average of $1 \mathrm{~min} 44 \mathrm{~s}$ to react to a new email notification by opening up the email application. The majority of emails, $70 \%$, were reacted to within $6 \mathrm{~s}$ of them arriving and $85 \%$ were reacted to within 2 min of arriving. $6 \mathrm{~s}$ is less than three rings of a telephone, and as the majority of employees enable such interruptions every $5 \mathrm{~min}$ the overall reaction time to an email message is almost as immediate as a telephone response. The time it takes the employees to recover from an email interrupt, and to return to their work at the same work rate at which they left it, was found to be on average $64 \mathrm{~s}$.

Fig. 1 shows different interrupt recovery times for the various different groupings of the subjects. Though only a few subjects qualified for certain categories the results show some interesting findings. The "worker" category has the quickest interrupt recovery time, at an average of $83 \mathrm{~s}$, followed by the "administrator" category, which took $110 \mathrm{~s}$. As only one subject was in the "manager" category the results are unrepresentative and cannot be compared against the "administrator" and the "worker" categories. If the number of subjects in the study were significantly higher, the male and female groupings could have been broken down as subcategories of "Administrator", "Worker" and "Manager". This could have given, though crudely, an insight into which gender is likely to handle interrupts more efficiently in the different 


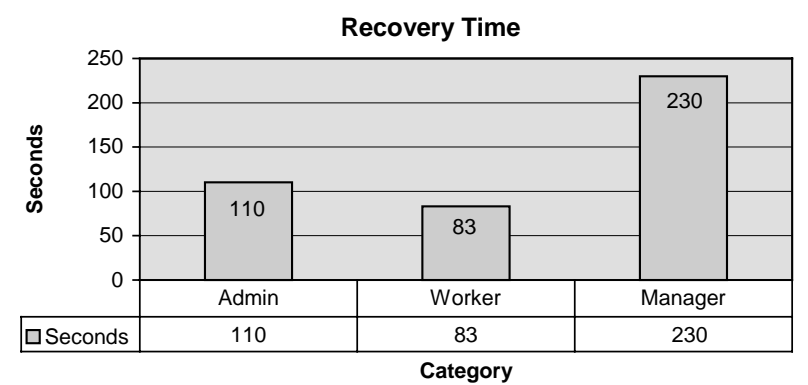

Fig. 1. A breakdown of interrupt recovery times per category in seconds.

kinds of jobs. However, the study showed that there is only a slight difference between the interrupt recovery times for females and males. The females are $14 \mathrm{~s}$ quicker at getting back into their work.

Through analysing individual employees a number of good email practices emerged; and combining these practices and getting employees to adopt them could increase employee effectiveness and aid in better interrupt handling. For example, a number of employees would only read their inbox when new email arrived to see whether the email was worth reading. They did this by being able to see three lines of the email, the subject line and the sender. This saved the employee time because many emails, especially junk emails, were deleted without even opening them because the employee could determine the nature of the email by the 3 lines of email on display. Another timesaving practice was to use the new email icon located in the system tray to access the newly arrived email. It may seem simple, but a number of employees minimised all the applications to get to their email application, which in some cases took some time.

There have been various observations about email and whether it has an interrupt recovery time associated with it, as the receiver of an email is perceived to deal with it at their own convenience (DeMarco \& Lister, 1999; Zijlstra Fred, Roe Robert, Leonora Anna, \& Krediet Irene, 1999; Soligen, Berghout, \& Latum, 1998). This study has shown that $70 \%$ of emails dealt with were viewed within $6 \mathrm{~s}$, which is quicker than letting the phone ring three times. Only a very small minority of employees would leave the email until they had come to a point where it was convenient to stop work and attend to the email. When the employee has been informed about the new email and chooses not to respond, might they be thinking, "I wonder who has sent me an email"? It is like being sent an interesting parcel through the post and having to resist the temptation not to open it until the current job has been finished. This behaviour is probably a part of human nature that will be difficult or impossible to change. It is therefore necessary to examine ways in which the level of interruption can be minimised.

\section{Analysis of methods for reducing email interruption effects}

DeMarco and Lister have described the high impact of phone calls in engineering environments: developers routinely receive 15 telephone calls a day, which can make the whole day non-productive (DeMarco \& Lister, 1999). The findings of the email analysis show that, on 
average, about $60 \mathrm{~s}$ is spent per email excluding recovery time, and a total of two minutes is spent if the recovery time is assumed for each email message. This compares well with the interruption reported for telephone calls (DeMarco \& Lister, 1999). Clearly email has less of an interrupt effect than the telephone although it is still significant. It is important, therefore, that any suggested methods for reducing the effect of email interrupt should not encourage employees to seek alternatives as this is likely to increase the interrupt effect.

The following methods for reducing the interrupt effect of email are considered.

1. Education of employees about the number of interrupts: In Solingen's research, educating employees about the negative effects of interrupts has decreased interruptions by $30 \%$ (Solingen, Berghout, \& Latum, 1998). Speculatively, if employee education on interrupt awareness was effective, a company could double the amount of useful emails without increasing the level of non-business emails. One of the findings of the research at the Danwood Group was that a large number of email messages received were not relevant to the person receiving them as they were sent to all staff. Many employees then used the reply to-all facility generating further non-relevant emails. Education on the importance of reducing this email by targeting email to only those who need to receive it is bound to have an overall beneficial effect. The company can assist this targeting by providing suitable email groups to enable the targeting to be performed simply and effectively.

Simple education could also assist employees to minimise the inconvenience of non-relevant emails. The employees who used the facility to display the first three lines of each message were able to make more effective use of their email monitoring activity. Not only did it enable non-relevant emails to be deleted immediately it also allowed employees to prioritise their handling of each message. If all employees used this facility it would reduce the effect of the widespread interruptions caused by email-to-all messages.

2. Educating employees about the nature of interrupts: The research at the Danwood Group showed that the average interrupt time taken for an email was about two and a half minutes. This was assuming that every email interrupt would generate an interrupt recovery time. In practice on some occasions two or more emails could be received at one time so this would further reduce the average interrupt recovery time for each interrupt. If educating employees of these facts could persuade employees to use email rather than telephone calls reducing telephone calls by 4 per employee per day it would in turn save $50 \mathrm{~min}$ recovery time as well as the time taken for the actual telephone calls. De Marco and Lister's research into telephone interrupt recovery times was carried out on software developers, and the $15 \mathrm{~min}$ it takes a software developer to recover from a telephone interruption is unlikely to apply to most of the employees studied at the Danwood Group. However, the 15-min interrupt recovery time gives an indication of the time that could be saved if an employee decided to use email instead of the phone for some of their communication.

3. Changing the settings of the email software: Microsoft Outlook 2000 has a facility, as many other email clients do, that allows the user to set the frequency of when the email application should check for new mail. The results at the Danwood Group showed that the majority of 
employees have their email application set to check for email every 5 min. Although many employees set their email applications to check for email every $5 \mathrm{~min}$, the nature of email means that it is unlikely to matter if an employee waits a little longer. It would be more productive to the user if the email was checked at an interval when interrupts would be less frequent and possibly even beneficial. Many people find that long periods of concentration on one single task reduces their effectiveness, and for that reason it can be beneficial to take a break and think about something else for a few minutes. The length of time a person can effectively concentrate on one task will vary from person to person, but typically a break after 45 min or so is likely to be beneficial. This gives an indication of how long an interval would be desirable for email interrupts. If employees set their email applications to check for email no more frequently than every $45 \mathrm{~min}$ (or whichever interval they find most suitable for themselves) then the interruption that does take place is clearly less disruptive and could even have a beneficial effect.

The research by Frazee showed that some employee could receive up to 100 emails each day. With the email software monitoring email every 5 min over an $8 \mathrm{~h}$ day this means that in the worst case these employees could have 96 interruptions in the day. The total interrupt recovery time would then be $102 \mathrm{~min}$. If the checking for incoming email is reduced to every 45 min this will mean there is a maximum of 11 interruptions in an $8 \mathrm{~h}$ day, with a total interrupt time of only 12 min per day. Setting the email software-checking interval to an even longer period would make still further time savings. The monitoring of the Danwood employees showed that the peak of email activity occurred at four points in the day; at the start of the day, just before lunch, just after lunch and at the end of the day. If employees could be persuaded to restrict their use of email to these four periods by checking for incoming email manually, removing the automatic checking, then arguably this would reduce the interrupt recovery time altogether.

4. Changing the method of incoming email notification: Most email applications allow different means of notifying the user of incoming email. These different means can give different levels of intrusion, as some are easier to ignore than others. For example, a prominent sound accompanying a pop-up dialog box has a far more intrusive effect than a small icon that appears in one corner of the screen; yet the user is just as aware of the incoming email whichever is used. A less intrusive notification method may encourage users to respond in their own time, at a moment which is more convenient for them, and which will give less of an interruption to their concentration on the job in hand.

5. Encourage the use of one line emails: It is noticeable that many employees used a verbose style when writing emails. An informal observation in this research suggested that $50 \%$ of emails communicated could be handled in a one-line message. A message expressed in one line is obviously quick to read and minimises the overall time spent reading emails. Furthermore, if the whole message is then put in the subject line, the reader need not even open the message and can decide what to do with the email very quickly.

To exploit the one line potential for email messages a sample of employees at the Danwood Group were provided with an in-house developed extra email facility. The objective was to 
develop an internal Short Message Service (SMS), which could be accessed through Outlook 2000. The short message activity was monitored and the results collated to see whether the Short Message Service had increased the effectiveness of communicating within the workplace, by reducing the time spent composing and reading emails. The SMS application was developed as an add-on for Outlook 2000 using the development features available within Outlook 2000 and Visual Basic for Applications (VBA). The Outlook 2000 add-on resulted in the Danwood Group employees having the ability to send a short message as an alternative to a traditional email message.

For the SMS email research programme to be a success the potential users needed some incentive to use the new system. For message senders, the incentive was that their messages automatically had high priority. For the receiver the message was displayed in the Inbox list of messages, eliminating the need to "open" each individual message. A different icon was used to indicate that the whole message was in the subject line, and the message was prefixed by "SMS:" to further emphasise this point. It was also imperative that the short message service was seamless and acted as an integral part of Outlook 2000. If the SMS service were difficult to use then the users would resort to sending traditional emails.

In a survey of the users who tried the SMS emails, $80 \%$ said they found the facility saved them time. A side effect was that users of the SMS facility learned to be more succinct with their messages in general so that even their traditional emails were shorter and better structured. Overall this experiment had a clear beneficial effect though this was not quantified as it was carried out at a different time to the WinVNC monitoring.

This research has shown that email messages do have some disruptive effect by interrupting the user, probably more than is generally assumed. This analysis has suggested that a number of methods can be employed to reduce this interrupt effect.

\section{Conclusion and guidelines for reducing email interruptions}

It is clear from the observations made that many employees could reduce the time lost to interrupts through simple changes of practice. The authors were able to make recommendations to the company that would allow more effective and efficient use of email, which in turn should make employees more productive. The recommendations given below are based only on the experience of the Danwood Group and therefore can only be considered to be applicable to that company. However, informal enquiries of other companies suggest that the experience at the Danwood Group is not likely to be unique, and so it is believed that other companies would also benefit from putting these recommendations into practice.

The findings of this research suggest that companies can significantly reduce the interrupt effect of email by following the set of recommended guidelines given below. These guidelines should reduce the effect on employee time and, as a result, increase employee effectiveness.

The recommended guidelines for email use in the workplace are as follows:

- Introduce training to all staff to inform them of the number and nature of interruptions and the effect on the organisation. 
- Restrict the use of email-to-all messages, and in particular reply-to-all messages. The use of more targeted email user groups may assist in this respect.

- Set up the email application to display in the inbox the sender, the subject and three lines of the email, so that the recipient can quickly determine if the email requires immediate attention.

- Set up the email application to check for email at no less than every $45 \mathrm{~min}$. It may be possible to eliminate the automatic checking for email altogether if employees can be encouraged to manually check for incoming messages at set times of day.

- Reduce the prominence of interruptions through turning off the new email alert dialogue box and email sound alerts.

- Encourage employees to use one line emails. If possible this should be done through the provision of an email add-on facility, but if this is not possible encouragement can be in the form of simple information and training.

This research has shown the value of measuring communication processes. The analysis of email has enabled the effect on employee time to be quantified and has given some surprising results. This has led to a series of recommendations that will enable the Danwood Group to make better use of email communication and increase employee effectiveness. The implication for managers in other companies is that if their own employees have similar practices in using email then the companies would also benefit from following these recommendations.

\section{References}

Boucsein, W. (1989). Experimental variation of time parameters during human-computer interaction in psychophysiological laboratory settings. Amsterdam: Elsevier Science Publishers.

Boucsein, W. (1993). Psychophysiology in the computer workplace-goals and methods. Amsterdam: Elsevier Science Publishers.

Briner, R.B. (1995). Beyond stress and satisfaction: understanding and managing emotions at work. Unpublished.

Broadbent, D. E. (1979). Human performance and noise. New York: McGraw-Hill.

Cambridge, AT\&T Laboratories. (2000). Windows Virtual Network Computing. http://www.cam-orl.co.uk/vnc/ winvnc.html: AT\&T Laboratories, Cambridge.

Daft, R. L., \& Lewin, A. Y. (1993). Where are the theories for the 'new' organizational forms. Organizational Science, 4, I-IV.

Davenport, T. H. (1997). Information ecology. New York: Oxford University Press.

DeMarco, T., \& Lister, T. (1987). Peopleware: Productive projects and teams. New York: Dorset House.

DeMarco, T., \& Lister, T. (1999). Peopleware: Productive projects and teams (2nd ed.). New York: Dorset House Publishing Company.

DilDog (2000). Back Orifice 2000. http://www.bo2k.com/indexdownload.html: Cult of the Dead Cow.

Fielden, J. (1960). Educating tomorrow's executives. Harvard Business Review, 38, 6-18+.

Frazee, V. (1996). Is e-mail doing more harm than good? Personnel Journal, 23.

Hartley, L. R., Morrison, D., \& Arnold, P. (1973). Stress and skills. In A. M. Colley J. R. Beech (Eds.), Acquisition and performance of cognitive skills. University of Leicester.

Henning, R. A., Sauter, S. L., Salvendy, G., \& Krieg, E. F. (1989). Microbreak length, performance, and stress in a data entry task. Ergonomics, 32, 855-864.

Johansson, G., \& Aronsson, G. (1984). Stress reactions in computerized administrative work. Journal of Occupational Behaviour, 5, 159-181.

Lotus. (2000). Lotus ScreenCam. http://www.lotus.com/home.nsf/welcome/screencam/: Lotus.

Mandler, G. (1964). The interruption of behaviour. In Nebraska Symposium on Motivation (pp. 163-219). 
Mandler, G. (1975). Mind and emotion. New York: Wiley. Reprint edition; Melbourne, Florida: Krieger, 1982. German edition; Denken and Fühlen. Paderborn: Junfermann, 1980.

Markus, L. M. (1994). Electronic Mail as the Medium of Managerial Choice. Organizational Science, 5, 502-525.

Mayo, E. (1933). The human problems of an industrial civilization. New York: Macmillan.

Nantz, K. S., \& Drexel, C. L. (1995). Incorporating electronic mail into the business communication course. Business Communication Quarterly, 58, 45-51.

Ovsiankina, M. (1928). Die wideraufnahme unterbrochener Handlungen. Psychologische Forschung, 11, 302-379.

Pekrun, R., \& Frese, M. (1992). Emotions in work and achievement. Chichester: Wiley.

Rasmussen, J. (1986). Information processing and human-machine interaction: An approach to cognitive engineering. Amsterdam: North-Holland.

Richardson T., Stafford-Fraser Q., Wood K. R., \& Hopper A. (1998). Virtual network computing. IEEE Internet Computing, 2, 33-38.

Sentinel. 2000. Windows Ranger. http://www.rangersuite.com/products/win_ranger/winr_functions.htm: Sentinel Products.

Solingen, R., Berghout, E., \& Latum, F. (1998). Interrupts: Just a minute never is. IEEE Software, 15, 97-103.

Visionsoft. 2000. I-SPY. http://www.visionsoft.com/products/ispy.htm: Visionsoft.

Watzlawick, P., Beavin, J., \& Jackson, D. (1967). Pragmatics of human communication. New York: Norton.

Zijlstra F. R. H., Roe R. A., Leonora A. B., \& Krediet I. (1999). Temporal factors in mental work: Effects on interrupt activities. Journal of Occupational and Organizational Psychology, 72, 163-185.

Tom Jackson is a Lecturer in Computer Science at Loughborough University. His research areas include HumanComputer Interaction (HCI), Modelling System Lifecycle Costings, Information System Analysis and Cost Effectiveness of IT Systems. He is currently conducting research into IT investment evaluation. Tom has a B.Sc. and a Ph.D. from Loughborough University.

Ray Dawson is a Senior Lecturer in Computer Science at Loughborough University. He has been lecturing at the University since 1987, teaching database development, systems analysis and design, and software project management. His research areas include software development working practices, software quality and cost. Recent research has been on empirical methods for quality improvement working with the Danwood Group, Rolls-Royce and A.A.H. He has a first degree and masters degree from Nottingham University. Ray Dawson is a Chartered Engineer and a Member of the British Computer Society.

Darren Wilson is the Information Systems Director at the Danwood Group Limited, which is based in the UK. He is a qualified accountant and his research interests include development of handheld applications, the cost effectiveness of IT systems and increasing efficiency through strategically replacing paper based systems with IT solutions. 